\title{
Images in Practice: Multifidus Muscle Dysfunction Characterized by Fat Infiltration in a Patient with Chronic Lumbar Back Pain
}

\author{
Hisham Kassem • Ivan Urits · Jamal Hasoon • Alan D. Kaye • \\ George Chesteen · Omar Viswanath (D)
}

Received: November 22, 2019 / Published online: December 27, 2019

(c) The Author(s) 2019

Keywords: Axial low back pain; Chronic low back pain; Fat infiltration; Mulifidus

\section{Key Summary Points}

Stability and functional movements of the lumbar spine comes inherently from the utility of the paraspinal muscles, most particularly the lumbar multifidus muscle.

In the setting of chronic lumbar pathology, healthy muscle is replaced with adipose tissue, a marker of weakening.

Enhanced Digital Features To view enhanced digital features for this article go to https://doi.org/10.6084/ m9.figshare.11336309.

\section{H. Kassem}

Department of Anesthesiology, Mount Sinai

Medical Center, Miami Beach, FL, USA

I. Urits · J. Hasoon

Department of Anesthesia, Critical Care, and Pain Medicine, Beth Israel Deaconess Medical Center, Harvard Medical School, Boston, MA, USA

\section{A. D. Kaye}

Department of Anesthesiology, Louisiana State

University Health Sciences Center, Shreveport, LA, USA

G. Chesteen

Department of Radiology, University of Nebraska

Medical Center, Omaha, NE, USA
Degeneration of the multifidus has been shown to contribute to intractable low back pain.

Further large observational studies may subsequently reveal the true incidence of low back pain in patients noted to have changes of the multifidus muscle evident on radiographic imaging, as well as treatment strategies to reduce and prevent the progression of fat infiltration.

\section{IMAGES IN PRACTICE}

Low back pain is one of the most common recurrent complaints in the general population

\section{O. Viswanath $(\bowtie)$}

Valley Anesthesiology and Pain Consultants -

Envision Physician Services, Phoenix, AZ, USA e-mail: viswanoy@gmail.com

O. Viswanath

Department of Anesthesiology, University of Arizona College of Medicine-Phoenix, Phoenix, AZ, USA

O. Viswanath

Department of Anesthesiology, Creighton University School of Medicine, Omaha, NE, USA 


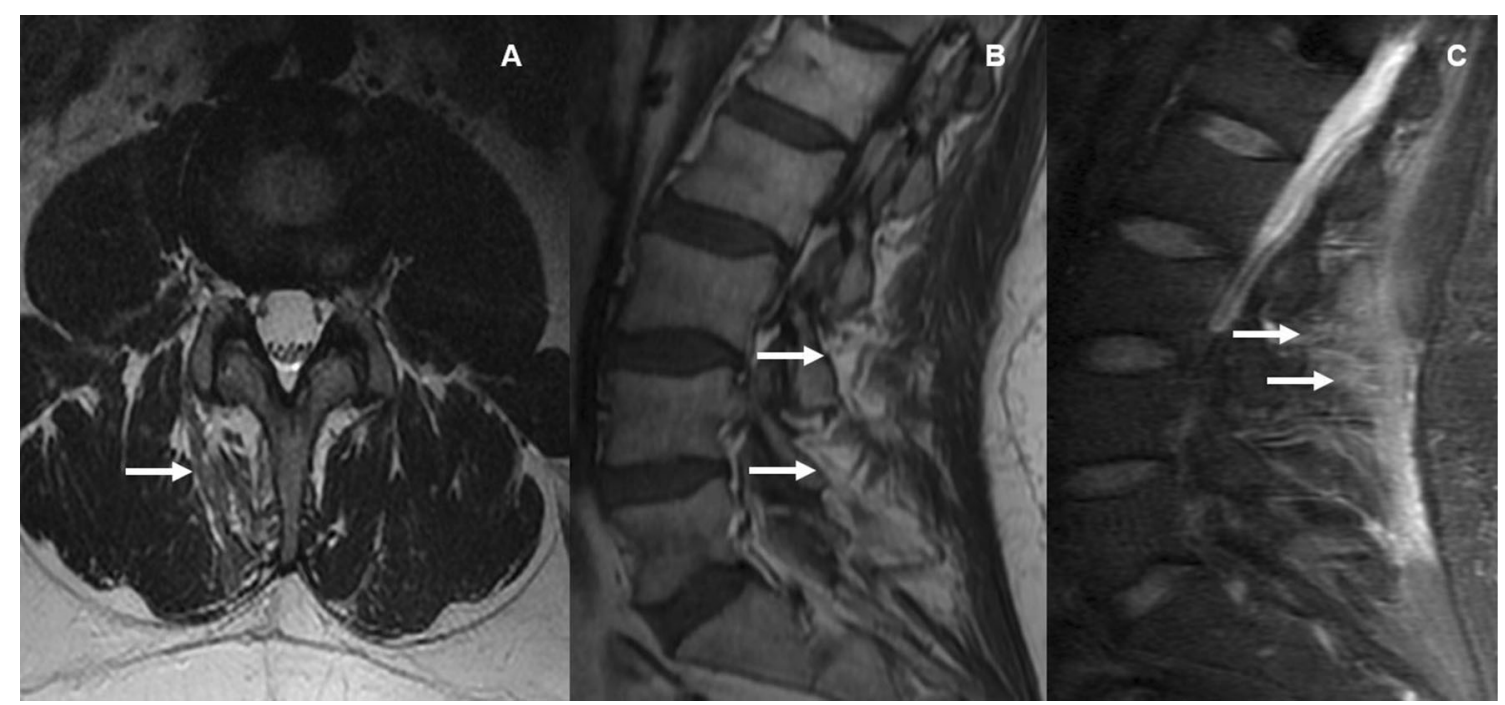

Fig. 1 a Axial T2-weighted magnetic resonance imaging (MRI), which demonstrates fat infiltration of the right multifidus muscle. b, c Sagittal T2-weighted MRI imaging

and carries a lifetime prevalence of $65-80 \%$ [1]. Stability and functional movements of the lumbar spine comes inherently from the utility of the paraspinal muscles, most particularly the lumbar multifidus muscle. In the setting of chronic lumbar pathology, healthy muscle is replaced with adipose tissue, a marker of weakening. Degeneration of the multifidus has been shown to contribute to intractable low back pain.

These images (Fig. 1a-c) are from a 46-year-old otherwise-healthy patient who presented with chronic intermittent low back pain radiating to the anterior thigh and down the medial calf bilaterally. The patient provided their informed consent to publish this article and all procedures were conducted as part of standard care/treatment. Magnetic resonance imaging (MRI) of the lumbar spine was remarkable for lumbar multifidus muscle atrophy with severe (grade 2) fat infiltration, more significant on the right than on the left (Fig. 1a, b). On short tau inversion recovery (STIR) sequence, there was diffusely increased signal uptake, consistent with atrophic changes within the multifidus muscle (Fig. 1c).

The multifidus muscle represents an essential stabilizer of the lumbar spine. The effect of chronic lumbar pathology on its function has which demonstrates long segment fatty changes of the right multifidus muscle and diffuse increased STIR signal indicating atrophic muscle

yet to be determined. Several studies have aimed to correlate the degree of fat infiltration and onset of symptoms with conflicting results that could suggest loss in muscle range of motion as a predictor of elevated pain [2]. In contrast, the relationship between patients with decreased muscle function and development of low back pain could be confounded by other factors including age, gender, duration of disease, and ethnicity [3]. Fatty infiltration in the multifidus muscle is a novel radiographic finding supportive of multifidus dysfunction in the setting of chronic lumbar pathology leading to low back pain. Further large observational studies may subsequently reveal the true incidence of low back pain in patients noted to have changes of the multifidus muscle evident on radiographic imaging, as well as treatment strategies to reduce and prevent the progression of fat infiltration.

\section{ACKNOWLEDGEMENTS}

Funding. No funding or sponsorship was received for this study or publication of this article. 
Authorship. All named authors meet the International Committee of Medical Journal Editors (ICMJE) criteria for authorship for this article, take responsibility for the integrity of the work as a whole, and have given their approval for this version to be published.

Disclosures. Hisham Kassem, Ivan Urits, Jamal Hasoon, and George Chesteen have nothing to disclose. Alan D. Kaye is a member of the journal's Editorial Board. Omar Viswanath is the Section Editor for Images in Practice.

Compliance with Ethics Guidelines. The patient provided their informed consent to publish article and all procedures were conducted as part of standard care/treatment.

Open Access. This article is distributed under the terms of the Creative Commons Attribution-NonCommercial 4.0 International License (http://creativecommons.org/licenses/ by-nc/4.0/), which permits any noncommercial use, distribution, and reproduction in any medium, provided you give appropriate credit to the original author(s) and the source, provide a link to the Creative Commons license, and indicate if changes were made.

\section{REFERENCES}

1. Urits I, Burshtein A, Sharma M, Testa L, Gold PA, Orhurhu V, Viswanath O, Jones MR, Sidranksy MA, Spektor B, Kaye AD. Low back pain, a comprehensive review: pathophysiology, diagnosis, and treatment. Curr Pain Headache Rep. 2019. https://doi.org/10. 1007/s11916-019-0757.

2. Hildebrandt M, Fankhauser G, Meichtry A, Luomajoki H. Correlation between lumbar dysfunction and fat infiltration in lumbar multifidus muscles in patients with low back pain. BMC Musculoskelet Disord. 2017. https://doi.org/10.1186/s12891-016-1376-1.

3. Orhurhu V, Urits I, Orhurhu MS, Odonkor C, Olatoye $\mathrm{D}$, Viswanath $\mathrm{O}$. Confounding variables in future studies assessing relationship between paraspinal muscles and low back pain. Spine J. 2019;19(6): 1132-3. https://doi.org/10.1016/j.spinee.2019.01. 012. 